\title{
Renewable energy integrated multi-terminal transmission system using wavelet based protection scheme
}

\author{
S.Chandra Shekar ${ }^{1}$, G.Ravi Kumar ${ }^{2}$, S.V.N.L Lalitha ${ }^{3}$ \\ ${ }^{1}$ Research Scholor, Koneru Lakshmaih Education Foundation, India \\ ${ }^{2}$ Professor, Departement of EEE, Bapatla Engineering College, India \\ ${ }^{3}$ Professor, Departement of EEE, Koneru Lakshmaih Education Foundation, India
}

\begin{tabular}{l} 
Article Info \\
\hline Article history: \\
ReceivedAug 21, 2018 \\
Revised Oct 19, 2018 \\
Accepted Feb 1, 2019 \\
\hline
\end{tabular}

Keywords:

Microgrid

Protection scheme

$\mathrm{PV}$ and wind sources

Wavelet multi-resolution

\begin{abstract}
The power plants behavior is crucial under faulted conditions and responses on protection systems. Major microgrid (MG) protection problem is the problem between the fault current in utilitygrid mode and microgrid mode. As conventional protection system doesn't offer solution for all MG protection challenge, but it needs advanced protection strategy. Protection system must response to both the utilitygrid and MG faults. Fast response of protection is necessary as early as possible if the fault is occurs on utilitygrid and if the fault is occurs on $\mathrm{MG}$, the protection scheme must seperate the small possible portion of MG to remove the fault. This work presents a typical MG protection scheme using digital relaying and satellite communication with wavelet detailed D1-coefficients of mother wavelet Bior 1.5. This research work is done for the detection, discrimination and locality of faults at distributed generators (DG's) integration in multi-terminal transmission system. The algorithm tested under various faults with fault inception angles (FIA), fault impedances and fault distance of feeder line.
\end{abstract}

Copyright $(02019$ Institute of Advanced Engineering and Science. All rights reserved.

\section{Corresponding Author:}

S. Chandra Shekar,

Research Scholor, Koneru Lakshmaih Education Foundation,

Vaddeswaram, AP, India.

Email: chandrasekharsavarapu@gmail.com

\section{INTRODUCTION}

Renewable energy generation of various technologies on small size capacity DG's are suitable where many micro power sources are linked to the distribution system and produce electricity nearer to demand requirements[1]. This may overcome the necessity of central power generation, transmission, distribution costs. A microgrid is the one which can be linked to utilitygrid during normal condition and separated from the utilitygrid in an isolated or island mode during fault condition. Since a decade, the evolution of MG has become an efficient way of integrating DG's in the electric network. However, besides these benefits, the microgrids raised a different hurdles, amongst these the problem of its protection [2, 3].In order to get high performance and better AC power quality of the converters, it is worthful to control directly the phase angle and magnitude of 3- $\Phi$ supply currents [4].The major hurdle is protection system of MG must respond rapidly for the both utilitygrid and MG faults also should seperate the MG from the utilitygrid to protect RES's and isolate the least priority part of MG during clearance of the abnormal conditions [5].

Power electronics based components are required for the Smart grids which are very crucial for the inter connection of variable RES's. It is important to choose settings of over-current relays are considered for grid topology, location, fault type and quantity of power generation. Otherwise, mal-operation may takes place. As conventional protection system doesn't give solution for all MG protection challenge, but it requires advanced protection strategy. The protection scheme must be proper secure operation of MG in 2 modes of operations [6]. The implementation of fault analysis of power network done with wavelet 
transforms (WT) in recent trends [7]. However, the works rarely mention about the locality of fault on multiterminal with renewable energy sources (RES). WT analyzes discontinuous signals of current during faults in time \& frequency domain. The proposed algorithm carried fault analysis on multi-terminal transmission with variable RES's connected system. Wavelet Multi-Resolution Analysis (WMRA) is used to detect, classify and discrimination of the faults with the use of detailed $\mathrm{D}_{1}$-coefficients of signals output of current using mother wavelet Bior1.5 [8]. The system is tested under various faults with various locations, FIA and at fault resistance and it is confirmed that the algorithm works efficiently.

\section{INTEGRATION OF RENEWABLE ENERGY WITH POWER GRIDS PROTECTION}

The MG interconnection makes the network more flexible from various regions with wide availability of DG's where ever high demand of electricity is required. Integration of DG's with conventional power to coordinate each other at different times for example solar energy on the day time and wind energy on overnight. The electricity demand of small islands with a peak value load of a few $100 \mathrm{~kW}$ could be completely supplied by RES's energy storage units to co-ordinate the supply and demand. Proper power network design requires extensive simulation and depends on load profile, wind, solar resources and the level of integration. The operation of a power grid involves the protection scheme for the detection of fault conditions and restores normal condition through the corrective measures $[9,10]$.

\section{WAVELET ANALYSIS}

WT is the tool it divides the data into various components of frequency, and then traces each signal with a resolution matched to its particular scale. For a given function $\mathrm{x}(\mathrm{t})$ the continuous wavelet transform is as follows:

$$
W T(a, b)=\frac{1}{\sqrt{a}} \int x(t) g\left(\frac{t-b}{a}\right) d t
$$

Where ' $a$ ' and ' $b$ ' are dilation, translation constants and ' $g$ ' is the WT function which is real.The mother wavelet Bior1.5 to be chosen according to type of application. A new method of detection, categorization and locality of faults using WMRA of the transient or discontinues currents are discussed [11]. Where the signals have transients or irregular discontinuities the WT concepts are used to analyze the signals particularly more efficient like the post faults voltage/current waveform. Mother wavelet Bior1.5 is used by translation and dilation for the transmission protection. So that WT is advantageous for analyzing transients signals [12].Wavelet was used for fault classification in TLs and specifically, third order Daubechies (db3) was used as the mother wavelet [13].

\section{PROPOSED SYSTEM MODELLING AND PROTECTION SCHEME}

An utilitygrid connected to hybrid MG shown in Figure1. PV array is connected to DC bus through DC-DC converter and a capacitorconnected for smoothen the high frequency ripples of the output of PV voltage [14]. Fortunately, the problems can be moderately overcome by integrating the DER's to form a hybrid Micro-grid system, power generation of one source overcome the limitation of the other power generation [15]. At any given time, to extract the maximum power generated by a solar cell, the solar System has tobe equipped with a maximum power point tracker. It helps to operate the PV system at the maximum output power point for a given set of conditions, thereby maximizing the array efficiency [16]. The various operating situations of the RES'slike Wind and solar PVconnected to the MG and their combinations have created and simulated in MATLAB/Simulink [17].A proposed test systemwith a transmission line in between Bus1, 2 with a distance $90 \mathrm{~km}$ is presented. A MG is formulated with comprises of RES's designed. The wind energy source of capacity 9MVA, 575V through a transformer of $575 \mathrm{~V} / 25 \mathrm{KV}$ is connected at Bus 3. A bus4 formulated with RES's of capacity $400 \mathrm{KVA}$ connected through transformer of $575 \mathrm{~V} / 25 \mathrm{KV}$. A Power system block and SIMULINK software is taken to simulate the test system.

Photovoltaic (PV) system has array of cells consists of PV material in which solar radiation converts to direct current and further dc is converted into the alternating current via inverter then it is connected to utilitygrid. Maximum power obtained from solar PV system directly proportional to solar irradiance intensity. Wind turbine operates like a prime mover coupled to DC generator.A PMW technique converts outputof DC generator to 3- $\Phi$ AC voltage. Whenever rotor blades strike the wind, wind turbine extracts maximum K.E from the wind. The complete protection scheme algorithm is provided below:

Step 1: Determination of phase currents

Int J Pow Elec \& Dri Syst, Vol. 10, No. 2, June 2019: 995 - 1002 
Step 2: Calculating detailed $\mathrm{D}_{1}$-coefficients and sum of detailed $\mathrm{D}_{1}$-coefficients.

Step 3: Comparison of sum of detailed $\mathrm{D}_{1}$-coefficients with threshold value

Step 4: Faults identification on terminals

Step 5: Type of fault classification on terminal comparing with threshold value.

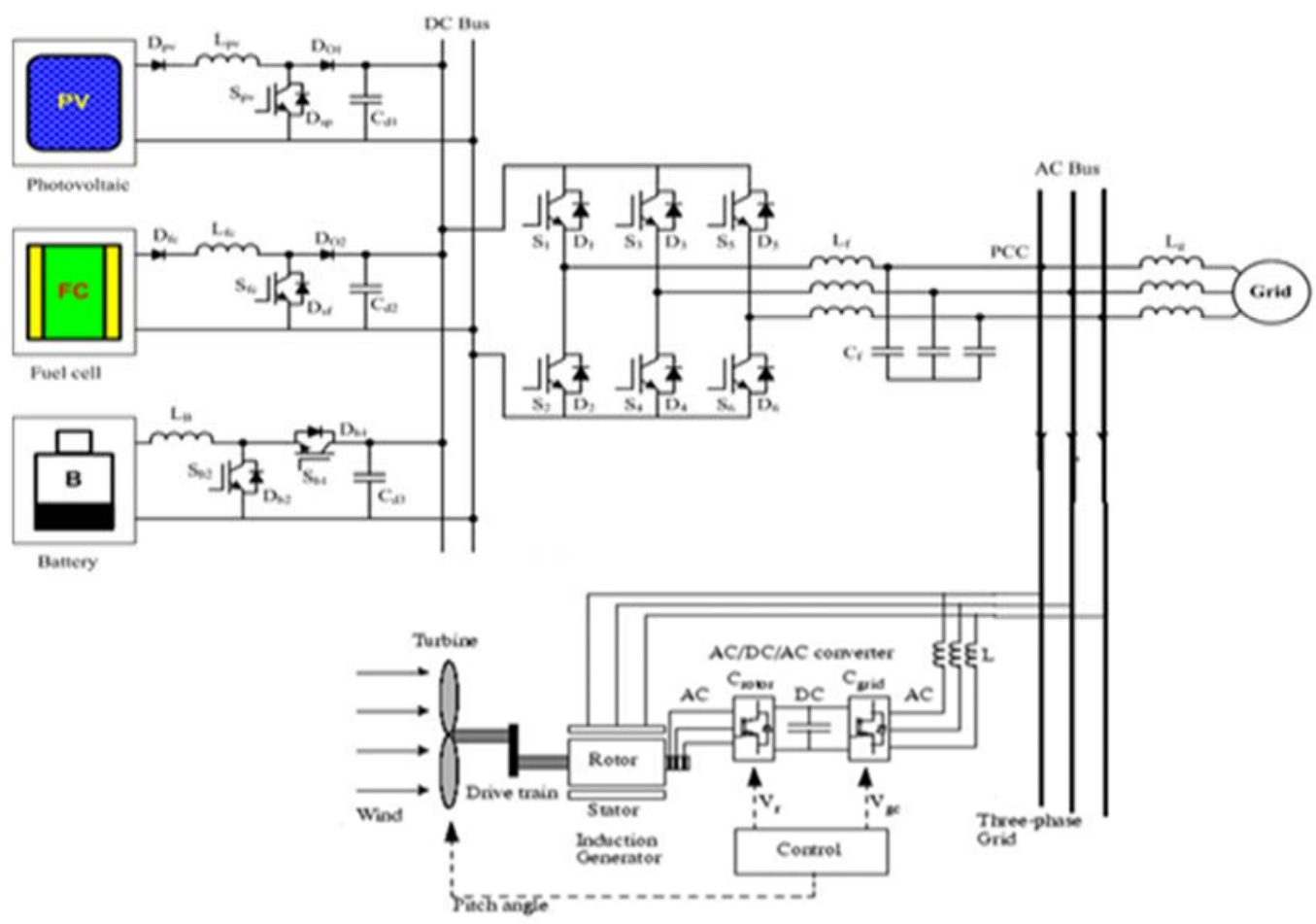

Figure 1. Proposed microgridconnected to utilitygrid system

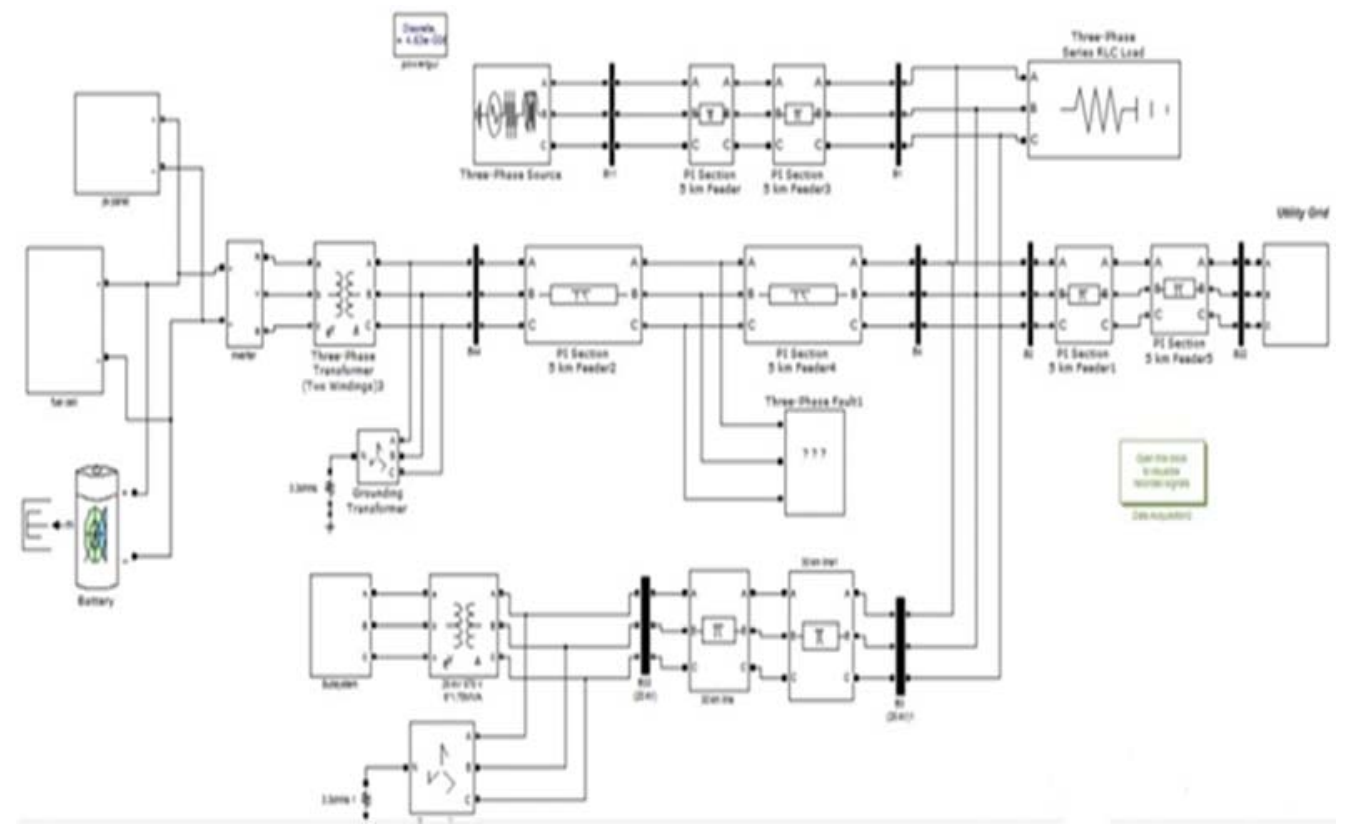

Figure 2. Simulation model for proposed system 


\section{RESULTS}

All terminals 3- $\Phi$ currents are evaluated with mother wavelet Bior.1.5 to obtain detailed $\mathrm{D}_{1}$ coefficients over a $1 / 2$ cycle length moving window. The detailed $\mathrm{D}_{1}$-coefficients are evaluated from the Bus 1 , 2, 3 and 4 to obtain detailed $\mathrm{D}_{1}$-coefficients. The Fault Index (FI) of every phase is calculated.The results are then plotted for various faults given below. The identification of faulted terminal is observed by detailed $\mathrm{D}_{1}$ coefficients of current indices of all terminals has largest value among other terminals shown in Figure 3 and indicating that the LG fault at terminal1. Figures 4-5 illustrates discrimination of fault at bus1 by observing Sum of detailed $\mathrm{D}_{1}$-coefficients of FI and FI of signals of current at Bus1. Figures 6-9 shows analysis of FI at various distances from bus 1 with LG fault, LL fault, LLG fault and 3- $\Phi$ fault at FIA $40^{\circ}$. It is concluded that faulted phase index values are high compared with healthy phase.
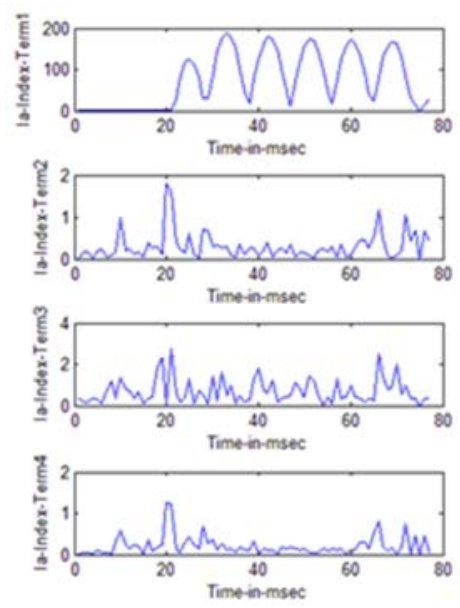
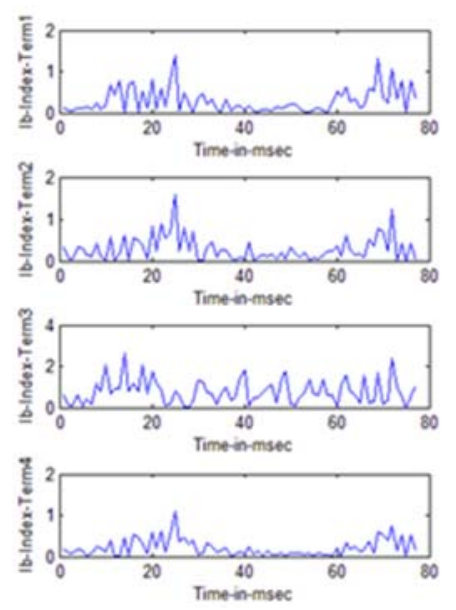
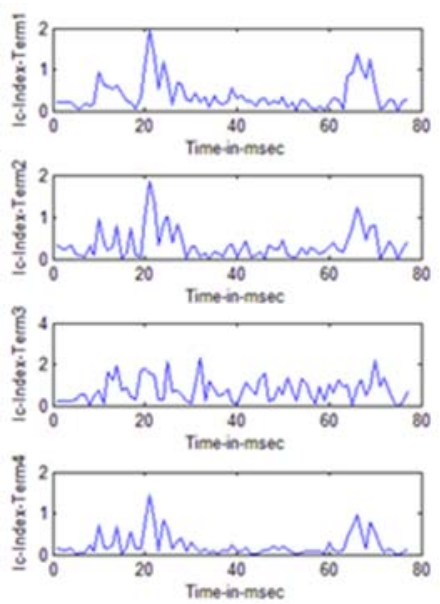

Figure 3. Variation of FI to discriminate type of fault from bus 1

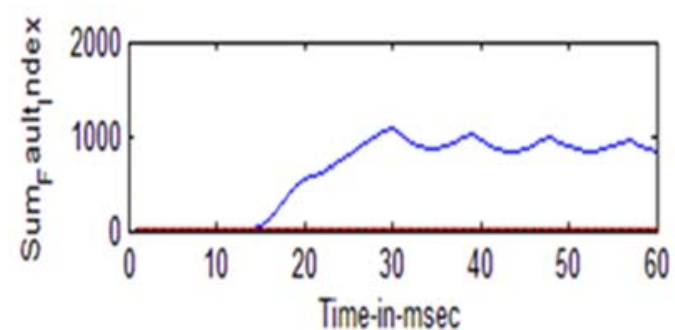

Figure 4. Variation of Sum of FI at terminall

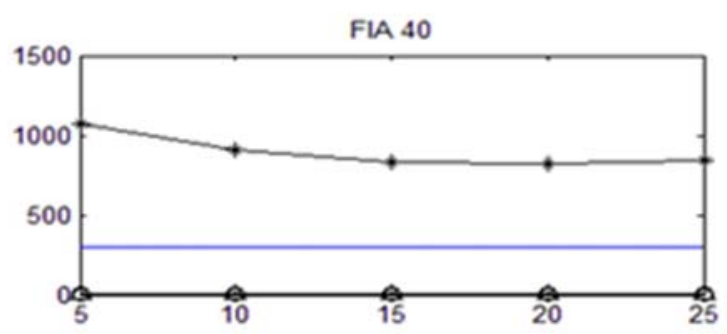

Figure 6. FI analysis at a distance from bus 1 with LG fault

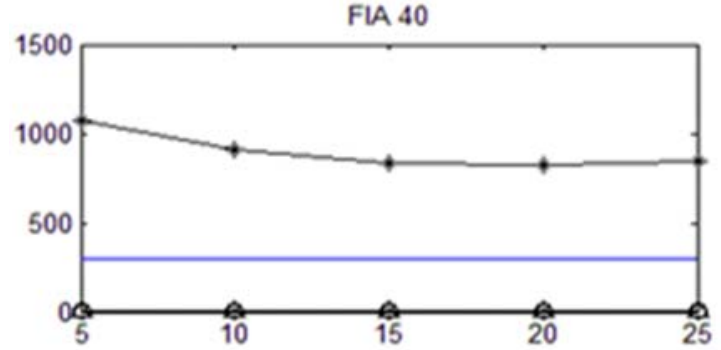

Figure 5. FI of signals of current at terminal1

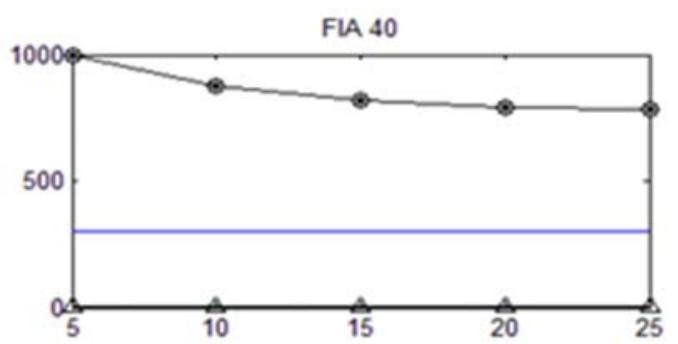

Figure 7. FI analysis at a distance from bus1 with LL fault 


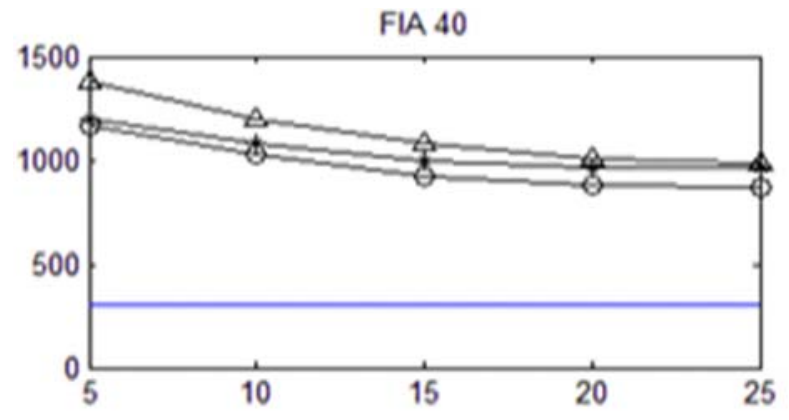

Figure 9. FI analysis at a distances from bus1 with 3- $\Phi$ fault

Figure10 shows detect and discriminate the LL fault at terminal 2(utility Grid). The identification of faulty terminal is observed by detail $\mathrm{D}_{1}$-coefficients of current indices of all terminals has largest value among the other terminals as shown in Figure 11 and indicating that the LLG fault at terminal 2. Figures12-13 illustrates discrimination of the fault at bus2 by observing Sum of detailed $\mathrm{D}_{1}$-coefficients of the FI and FI of signals of current at Bus2. Figure 14-17 shows the analysis of FI at various distances from bus_2(Utility Grid) with Single line-ground (LG), double line (LL), Double line-ground (LLG) and 3- $\Phi$ fault at FIA $20^{\circ}$. It isconcluded that faulted phase index values are high compared with healthy phase.
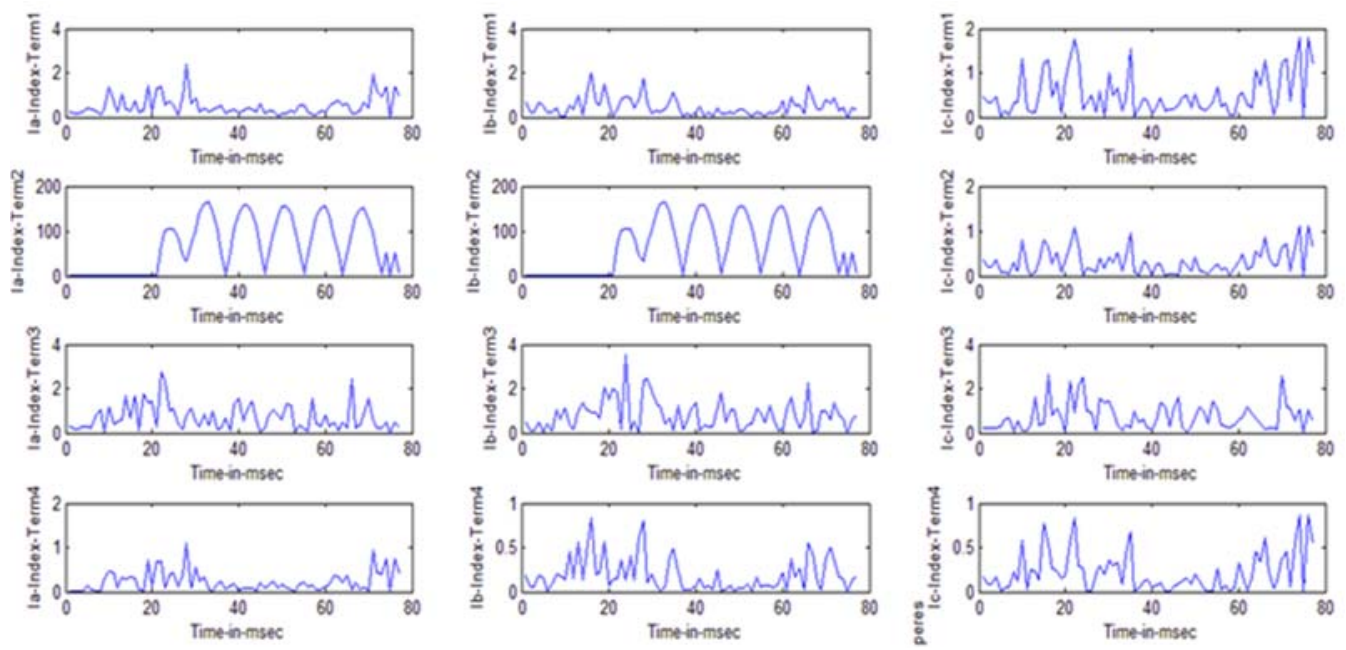

Figure 10. Variation of FI to discriminate the type of fault from bus 2(Utility Grid).
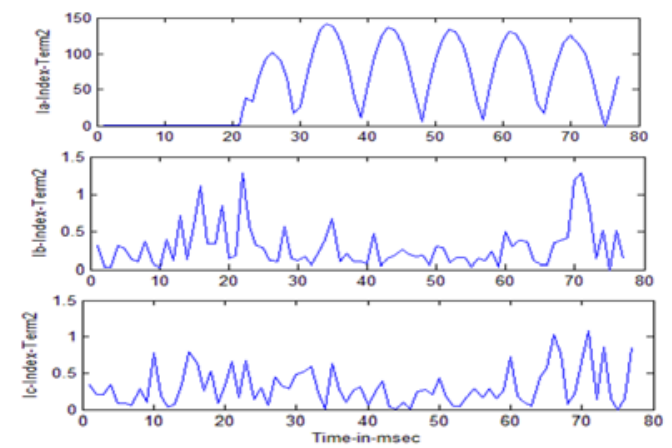

Figure 11. Variation of FI to discriminate the type of fault from bus2 (AG Fault) 


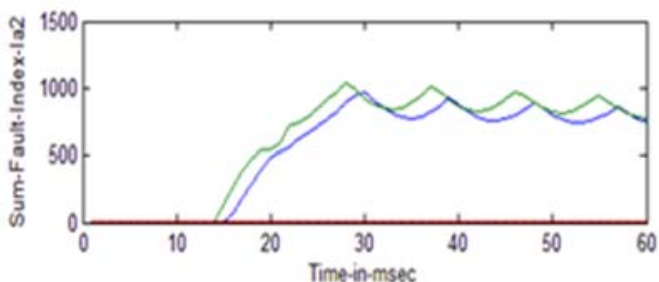

Figure 12. Parameters variation at bus2 (Utility grid) Sum of FI

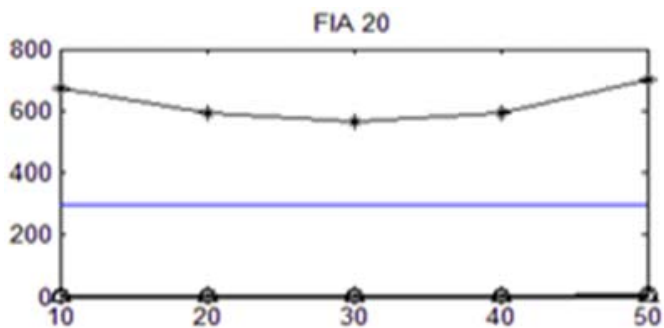

Figure 14. FI analysis at a distances from bus_2(utility Grid) with LG fault

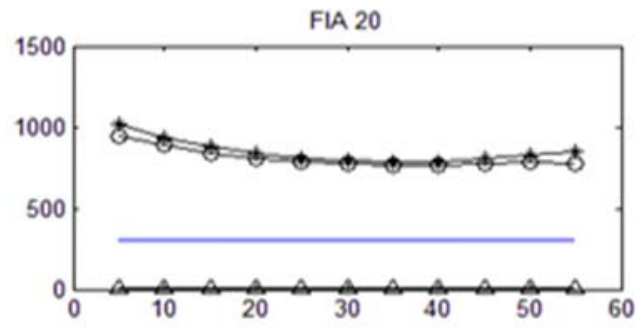

Figure 16. FI analysis at a distances from bus2 (utility Grid) with LLG fault

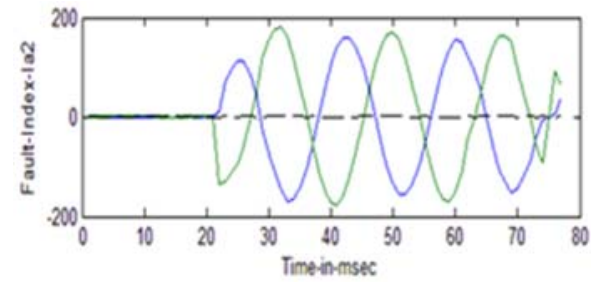

Figure 13. Parameters variation at bus2 (Utility grid FI of current)

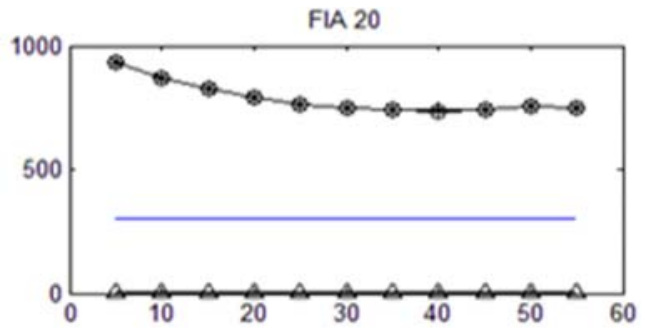

Figure 15. FI analysis at a distances from bus2 (utility Grid) with LL fault

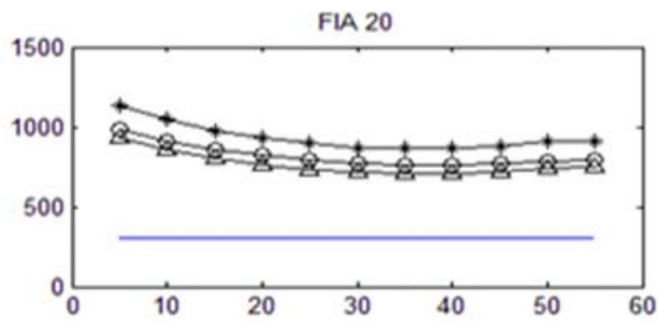

Figure 17. FI analysis at a distances from bus2 (utility Grid) with 3- $\Phi$ faul

Figures 18-19 illustrates discrimination of the fault at bus2 by observing Sum of detailed $\mathrm{D}_{1-}$ coefficients of the FI and FI of signals of current at Bus3. Figures 20-21 shows analysis of FI at various distances from bus 3 (Wind source) with LG fault and LLG fault and 3- $\Phi$ fault at FIA $60^{\circ}$. It is concluded that faulty phase index values are high compared to healthy phase.

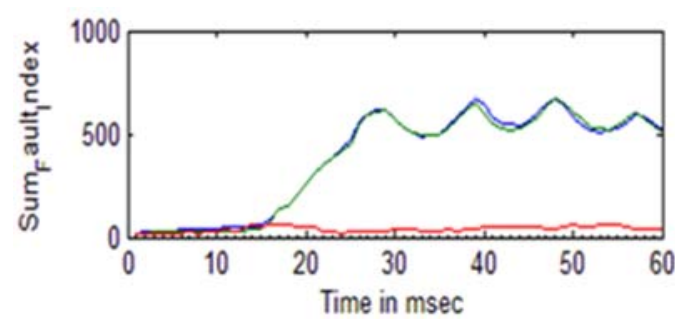

Figure 18. Parameters variation at bus3 (Wind source) Sum of FI

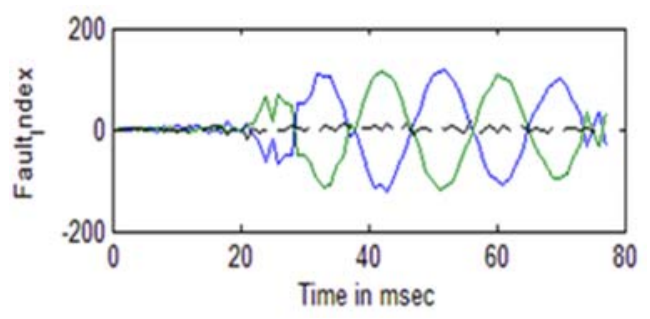

Figure 19. Parameters variation at bus3 (Wind source) Current 


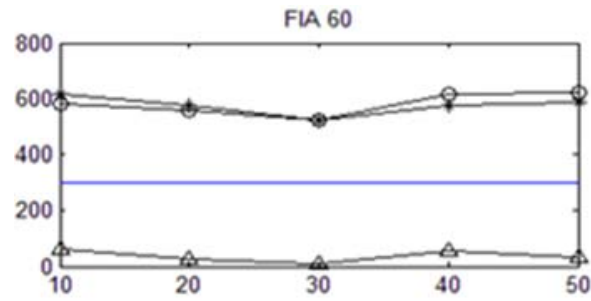

Figure 20. FI analysis at a distances from bus3 (Wind source) with LLG fault

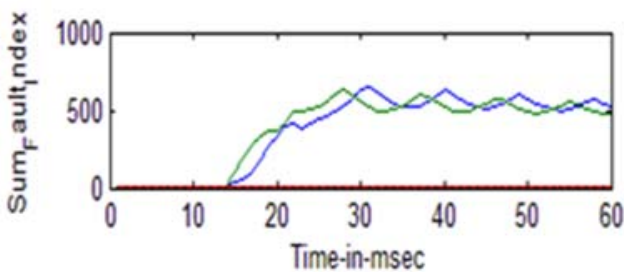

Figure 22. Parameters variation at bus 3 (PV source) Sum of FI

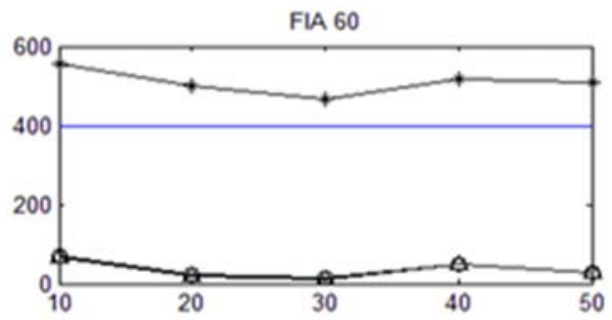

Figure 21. FI analysis at a distances from bus3 (Wind source) with LG fault

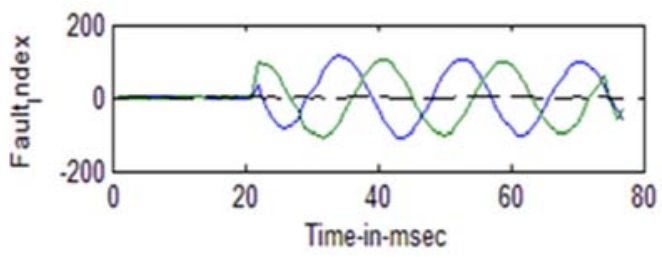

Figure 23. Parameters variation at bus 3 (PV source) FI

Figures 24-25 shows that Analysis of FI at various distances from bus3 (wind energy source) with LG fault, LLG fault at FIA $40^{\circ}$. It is concluded that all the index values are below the threshold value except faulty phase values. The proposed protection scheme is fast, accurate and reliable for faults on multi-terminal transmission network with MG containing RES's generation using WMRA.

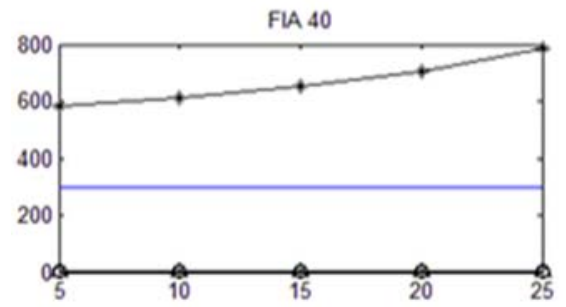

Figure 24. FI analysis at a distances from bus4 (PV source) with LG fault

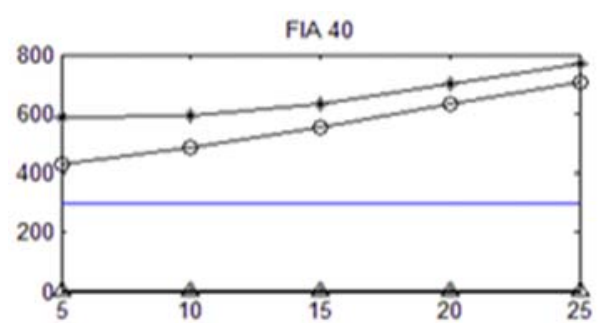

Figure 25. FI analysis at a distances from bus4 (PV source) with LLG fault

\section{CONCLUSION}

The major problem occurred in MG protection related to large difference between utility grid and MG mode fault currents are studied. The determination of the time must be small when it is islanded from the utilitygrid in response to under abnormal conditions. Protection system is proper synchronization and reliable method of protection for the effective tripping under fault condition. In this paper, the test system is created and simulated using the power system block with SIMULINK software and the analysis is done by WMRA to detection, categorization and locality of faults on transmission network. A Detailed $\mathrm{D}_{1}$-coefficients of signals of current using mother wavelet Bior.1.5 are used to detect and classify of fault less than a half cycle. The proposed protection scheme is found to be fast, accurate and reliable for various types of faults on multiterminal transmission network with microgrid containing RES's generation. 


\section{REFERENCES}

[1] Electric Energy Storage Technology Options: A White Paper Primer on Applications, Costs, and Benefits. EPRI, Palo Alto, CA, 2010.

[2] W. Feero, D. Dawson, J. Stevens, "Protection Issues of the Micorgrid Concept".

[3] Z. Bo. "The challenge of protecting microgrids". Alstom Grid, 2011.

[4] N. Chaitanya, P. Sujatha, K. Chandra Sekhar "Current Controller Based Power Management Strategy for Interfacing DG Units to Micro Grid”International Journal of Electrical and Computer Engineering(IJECE),Vol. 7, No. 5, October 2017, pp. 2300 2308.

[5] W. E. Feero, et al., "White paper on protection issues of the microgrid concept", 2002.

[6] H. Nikkhajoei and R. H. Lasseter, "Microgrid Protection," IEEE PES General Meeting, Tampa, 24-28 June 2007, pp. 1-6.

[7] Oudalova and A. Fidigattibfd, "Adaptive Network Protection in MICROGRID," 2011.

[8] P.Makming, S.Bunjongjit, A.Kunakorn, S.Jiriwibhakorn, M.Kando, "Fault Diagnosis in Transmission Lines Using Wavelet Transform Analysis", IEEE/PES Transmission and Distribution Conference and Exhibition.

[9] Ravi Kumar Goli, Abdul GafoorShaik, S.S Tulasi Ram "A transient current based double line transmission system protection using fuzzy-wavelet approach in the presence of UPFC", Electrical Power and Energy Systems, Vol. 70 91-98, 2015.

[10] A. Oudalov, et al., "Novel Protection Systems for Microgrids", 2009.

[11] S. Ustun, C. Ozansoy and A. Zayegh, "A Microgrid Protection System with Central Protection Unit and Exensive Communication," Proceedings of the 10th International Conference on Environment and Electrical Engineering, Rome, 8-11 May, pp. 1-4, 2011.

[12] S.G.Mallat, "A theory for multi resolution signal decomposition: The wavelet representation", IEEE Trans. Pattern Anal. Machine Intell, vol.11, pp.674-693, July 1989.

[13] Abdelgayed, T.S., Morsi, W.G. and Sidhu, T.S. "A New Harmony search approach for optimal wavelets applied to fault classification". IEEE Transactions on Smart Grid, 2016.

[14] T. B. Littler and d. J. Morrow. "Wavelets for the Analysis and Compression of Power System Disturbances", IEEE Transactions on Power Delivery, vol. 14, pp. 358-364, Apr. 1999.

[15] K. M. Priyadharshini, S. Srinivasan, C. Srinivasan "Detection of Power Quality Disturbances in Micro Grid Connected Power System" TELKOMNIKA Indonesian Journal of Electrical Engineering, Vol. 14, No. 1, April, pp. 9 15, 2015.

[16] Omar Mohammed Benaissa, Samir Hadjeri, Sid Ahmed Zidi "Modeling and Simulation of Grid Connected PV GenerationSystem Using Matlab/Simulink" International Journal of Power Electronics and Drive System (IJPEDS), Vol. 8, No. 1, March, pp. 392 401, 2017.

[17] Mohsen Akbari, SeyedMasoudMoghaddas-Tafreshi, MasoudAliakbarGolkar, "Wavelet-Based Multi-Resolution Voltage Controller in A Hybrid Ac/Dc Microgrid”,PrzegladElektrotechniczny (Electrical Review), ISSN 0033-2097, R. 88 Nr 8/2012. 